\title{
PEMROGRAMAN BERBASIS OBJEK
}

\author{
Sutriana $^{1}$ \\ ${ }^{1}$ Mahasiswa Program Studi Informatika Universitas Mitra Indonesia
}

\begin{abstract}
ABSTRAK
Di era kemajuan teknologi seperti sekarang ini, Website menjadi hal yang sudah tidak asing lagi terdengar pada telinga kita, kususnya dalam dunia internet. Meskipun sudah banyak orang mempunyai homepage di internet baik yang menggunakan ISP maupun server web gratis, tetapi pada umumnya homepage tersebut bersifat statis dan tidak dapat berinteraksi dengan pengunjung web.

Kebanyakan orang pada umumnya hanya berperan sebagai pengguna dan sebagian kecil saja yang mengetahui proses dibaliknya dikarenakan tidak menguasai pemrograman web. Pada dasar pembuatanya, sebuah homepage yang dapat berinteraksi dengan pengunjung website atau homepage dinamis tidak diperlukan kemampuan pemrograman yang tinggi.
\end{abstract}

\section{BAB 1 \\ Pendahuluan}

\subsection{Latar belakang}

Ada saat ini perkembangan dan kemajuaan teknologi informasi dan komunikasi telah berkembang dengan sangat pesat.Berbagai kemudahan memperoleh informasi dari berbagai penjuru dunia dapat kita nikmati dalam hitungan detik. Pada saat jaman dahulu kala teknologi sebagai sesuatu yang tidak mungkin, kini telah menjadi kenyataan.

Diantara teknologi informasi yang hampir disetiap tempat kita temukan adalah komputer.Sekarang komputer sangat berkembang pesat hampir setiap tahun komputer selalu mengalami perkembangan.Sedangkan model dan design dari komputer itu sendiri juga mengalami perkembangan. Dulu apabila orang ingin menggunakan komputer maka hanya bisa dikantor atau dirumah, tetapi sekarang mereka bisa menggunakan komputer tersebut dimana saja yang mereka inginkan.

Software yang kita gunakan sekarang ini tidak serta merta muncul begitu saja melainkan melalui proses yang panjang dalam evolusinya. Hal ihwal munculnya komputer mungkin dapat dilihat dalam kilas balik sejarah sejak digunakannya Abacus - ditemukan di Babilonia (Irak) sekitar 5000 tahun yang lalu - sebagai alat perhitungan manual yang pertama, baik di lingkup sekolah maupun kalangan pedagang, saat itu. Pada tahun 1940, era baru komputer elektrik dimulai sejak ditemukannya komputer elektrik yang menerapkan sistem aljabar Boolean. 


\subsection{Maksud dan Tujuan}

1. Untuk memberikan sebuah gambaran bahwa dalam mempelajari dan membuat web menggunakan PHP sebenarnya tidak terlalu sulit.

2. Agar pengguna internet pada khususnya dapat lebih mengembangkan potensi diri, dan tidak hanya sebagai pengguna saja tetapi dapat berperan sebagi pembuat suatu alamat web (homepage) yang dinamis. 


\section{BAB 2 \\ Pembahasan}

\subsection{Pengertian Software}

Software disebut dengan perangkat lunak, merupakan kumpulan beberapa perintah yang dieksekusi oleh mesin komputer dalam menjalankan pekerjaannya.perangkat lunak ini merupakan catatan bagi mesin komputer untuk menyimpan perintah, maupun dokumen serta arsip lainnya.

Merupakan data elektronik yang disimpan sedemikian rupa oleh komputer itu sendiri, data yang disimpan ini dapat berupa program atau instruksi yang akan dijalankan oleh perintah, maupun catatan-catatan yang diperlukan oleh komputer untuk menjalankan perintah yang dijalankannya. Untuk mencapai keinginannya tersebut dirancanglah suatu susunan logika, logika yang disusun ini diolah melalui perangkat lunak, yang disebut juga dengan program beserta data-data yang diolahnya.Pengeloahan pada software ini melibatkan beberapa hal, diantaranya adalah sistem operasi, program, dan data.Software ini mengatur sedemikian rupa sehingga logika yang ada dapat dimengerti oleh mesin komputer.

Kebanyakan masyarakat saat ini membagi komputer menjadi dua bagian .Bagian pertama adalah hardware yang merupakan perangkat fisik yang ada di dalam komputer. Dan bagian yang kedua adalah software komputer, yang memberitahukan hardware mengenai apa yang harus dilakukan dan bagaimana melakukannya. Apabila diibaratkan bahwa komputer adalah makhluk hidup, maka hardware adalah tubuhnya seperti mata untuk melihat, paru-paru untuk bernapas dan bagian tubuh lainnya, sedangkan perangkat lunak atau software diibaratkan sebagai kepintarannya, seperti memproses gambar yang dilihat mata, memerintahkan tangan untuk mengangkat objek, dan memaksa tubuh untuk menarik nafas dengan menggunakan paru-paru. Hardware Komputer, menjadi bagian dari mesin, dan hanya mengerti dua konsep dasar yaitu menyala (on) dan mati (off), konsep on dan off tersebut dinamakan binary. Software komputer dikembangkan agar binary dapat menjadi jalan untuk memberitahukan komputer hardware dalam melakukan tugasnya. Software Komputer menterjemahkan dan mengarahkan pengguna komputer agar mengerti mengenai apa yang dapat dilakukan oleh komputer hardware.

Sebagian besar dari software komputer dibuat oleh programmer dengan menggunakan bahasa pemrograman.Programer menuliskan perintah dalam bahasa pemrograman seperti layaknya bahasa yang digunakan oleh orang pada umumnya dalam melakukan perbincangan.Perintah-perintah tersebut dinamakan "Source Code".Program komputer lainnya dinamakan Compiler yang digunakan pada source code, dan kemudian mengubah perintah tersebut ke bahasa yang dapat dimengerti oleh komputer.Dan hasilnya dinamakan program executable (EXE).Software komputer dibagi menjadi dua kategori utama yaitu sistem software dan software aplikasi.Sistem software menyajikan program yang dapat mengijinkan hardware berjalan dengan semestinya.Software aplikasi menyediakan program yang mengijinkan pengguna untuk melakukan sesuatu disamping menjalankan hardware. 


\subsubsection{Jenis Sofftware}

Secara tak sadar, ketika kita menggunakan komputer, sebenarnya kita telah menggunakan software.Software atau perangkat lunak adalah semua program yang digunakan untuk menjalankan komputer atau perangkat lainnya.Secara umum, ada dua jenis software.Pertama adalah software aplikasi.Software aplikasi adalah software yang dibuat untuk tujuan atau kepentingan spesifik, contohnya Notepad untuk teks editor, Winamp untuk memutar file audio, dan sebagainya.Kedua adalah software sistem. Software sistem adalah software yang menjadi tempat semua software aplikasi berjalan .Contohnya adalah Microsoft Windows, Linux, Mac OS, dan sebagainya.

Menurut cara memperolehnya, software dapat dibedakan menjadi beberapa jenis. Jenis pertama adalah freeware.Software yang bersifat freeware dapat digunakan tanpa biaya, namun masih memiliki batasan atas hak cipta pengguna. Maksudnya, meskipun kita menggunakan freeware tersebut kita tidak boleh melanggar hak cipta atas software tersebut, misalnya penggandaan untuk orang lain atau menggunakan software tersebut untuk kepentingan lain. Biasanya freeware didistribusikan tanpa disertai dengan kode program yang bersangkutan.Lalu jika kita tidak perlu membayar.

\subsubsection{Bahasa Pemrograman PHP}

\section{Sistem Operasi}

Sistem operasi merupakan sofware yang pertama kali dibaca oleh komputer pada saat booting sebagai dasar pengoperasian komputer.Terdapat 2 jenis sistem operasi berdasarkan tampilan antarmuka kepada penggunanya (user interface) yaitu yang berbasis CUI (Character User Interface) dan berbasis GUI (Graphical User Interface). Sistem operasi berbasis CUI, misalnya : DOS (Disk Operating Sistem) dan Sistem Operasi UNIX dan Linux pada mode terminal atau konsol. Sedangkan sistem operasi berbasis GUI, misalnya : Microsoft Windows 9x, 2000, NT, XP, serta sistem operasi UNIX dan Linux yang telah mendukung GUI.

\section{Program Bantu dan Program Tambahan}

Program bantu (utility) merupakan program yang digunakan untuk mengisi kekurangan atau menampilkan kembali file suatu sistem operasi yang terhapus. PC Tools dan Norton Utilities merupakan contoh dari program ini.Salah satu dari kelemahan DOS adalah tidak mampu bekerja di sistem jaringan.Oleh karena itu beberapa perusahaan membuat program tambahan yang dapat mengubah sistem DOS tersebut (single user atau stand alone system) menjadi sistem operasi yang dapat digunakan oleh banyak pemakai (multiuser).Netware, Token $\mathrm{R}$ ing dan Lantastic merukan contoh-contoh program ini.

\section{Bahasa Komputer (Computer Language)}

Computer Language merupakan bahasa yang digunakan untuk membuat program komputer.Disebut bahasa karenacomputer language memiliki kosa kata dan tata bahasa yang harus ditaati oleh pemakainya.

Yang termasuk dalam jenis ini adalah :

a. Low Level Language, merupakan bahasa tingkat rendah karena sulit dipahami dan hanya dapat dimengerti oleh pembuatnya. Yang termasuk program ini adalah bahasa mesin assembly language 
b. High Level Language, merupakan bahasa tingkat tinggi karena menggunakan kata-kata yang mudah dimengerti. Contoh dari program ini adalah BASIC, PASCAL, FORTRAN, dsb.

Ada pula beberapa tipe software, diantaranya :

\section{a. Software Games}

Jenis software ini termasuk dalam kategori entertainment atau hiburan, software ini memiliki berbagai macam jenis.Jenis-jenis tersebut seperti MMOs (Massive Multiplayer Online games), first-person shooters, action games, roleplaying games, and game petualangan.

\section{b. Software Driver}

Program ini mengijinkan komputer untuk dapat berinteraksi dengan perangkat hardware tambahan seperti printer, scanner, dan video cards.

c. Software Pendidikan

berbeda dengan jenis program sebelumnya, software pendidikan ini dapat mengajarkan apapun dari komputer, melakukan aktifitas yang berhubungan seperti mengetik atau berbagai macam jenis pendidikan lainnya seperti kimia.

d. Media player dan pengembangan software media lainnya

Software yang dibuat untuk dapat memainkan atau mengedit media digital seperti file music atau video.

\section{e. Software Produktifitas}

Jenis software ini mengijinkan pengguna untuk lebih produktif baik itu dalam menjalankan bisnis atau menjalankan aktifitas produktif lainnya.Contoh dari software ini adalah software pengolah huruf (Ms Words), Software pengatur database, software presentasi dan beberapa software lainnya.

\section{f. Operating sistem}

software yang merupakan sumber dari software lainnya yang dapat mengijinkan software lainnya untuk berjalan. Contoh dari software operating sistem ini adalah Window Vista, Mac OS X dan Linux, Apple, Machintos dll, dan pada software inilah program aplikasi lainnya di install.

\section{g. Software Aplikasi}

Software yang diinstal pada komputer yang sesuai dengan os yang ada, dimana software aplikasi ini diinstal sesuai dengan kebutuhan User (Pengguna) contohnya, MS Office (Ms Word, Ms Excell, Ms Power Point dll), Software Grafis (Adobe Photoshope, Corel Draw, Autocad dil)

\section{h. Software Program}

Software yang berfungsi untuk membuat aplikasi-aplikasi program (Membuat Program baru) seperti program Games, Program data Base, Program Web dll, Contoh Software Program : Visual Basic, Cobol, C++, Program PHP dll

\section{i. Software Aplikasi Tools}

Program-program yang berfungsi untuk mempercepat, memperbaiki, dan mempermudah pengoperasian computer 


\section{BAB 3 \\ Penutup}

\subsection{Kesimpulan}

Pembuatan web menggunakan pemrograman PHP mempunyai berbagai macam kelebihan dan keunggulan bila dibandingkan dengan menggunakan program lain yang sejenis. Berbagai macam kemudahan yang ada pada program PHP sangat fleksibel dan akan memberikan kemudahan dalam aplikasinya. Sebagai contoh, data masukkan dalam suatu form html secara otomotis di-variabel-kan dan dapat digunakan langsung, sehingga tidak perlu memparsing apa yang disebut query string.

Konektivitas Database cukup kuat dengan dukungan native-driver untuk sekitar 15 database paling populer plus ODBC. PHP mendukung sejumlah besar protokol seperti POP3, IMAP dan LDAP. PHP 4 juga mempunyai dukungan baru untuk Java dan arsitektur pendistribusian objek (COM dan CORBA), membuat n-kali pengembangan untuk pertama kali. PHP tidak mendukung closed-source. Sebagai contoh komputer Apple dan Microsoft tidak dapat bekerjasama dengan proyek open source seperti PHP.

Berbagai keunggulan yang dimiliki oleh PHP sangat berperan penting dalam perkembangan dunia teknologi khususnya dalam bidang internet dan penyebaran informasi. Secara tidak langsung perkembangan tersebut juga akan mempengaruhi terhadap berbagai aspek kehidupan manusia.

\subsection{Saran}

Sebelum membuat sebuah script di dalam PHP sebaiknya terlebih dahulu memahami tentang HTML dan dasar-dasar pemrograman $(\mathrm{C} / \mathrm{C}++)$ karena pemahan yang cukup dalam pemrograman dasar $(\mathrm{C} / \mathrm{C}++)$ akan lebih mempermudah dalam aplikasi pembuatan sebuah scipt di dalam program PHP. 


\section{Referensi}

http://fikriarfiana.blogspot.com/2013/03/tugas-makalah-1-sistem-berorientasi.html https:// blogdosen.com

https://aliyhafiz.com

http://softwareinstalasi.blogspot.com

http://www.anneahira.com/komputer/software-komputer.htm

$\underline{\text { http://www.cs.ucl.ac.uk/teaching/syllabus/ug/1b12.htm }}$

http://rina-aryani.blogspot.com/2009/11/makalah-software.html

Trivena, A. I., \& Hafiz, A. (2019). Membangun Aplikasi Penyewaan Lapangan Futsal Pada Club Sport Bandar Lampung Berbasis Web. Jurnal ONESISMIK, 3(3), 155-166. 